\title{
MEDALLA FRANCISCO DÍAZ
}

\author{
J.M GIL-VERNET
}

Actas Urol Esp. 27 (1): 3-9, 2003

$\mathrm{P}_{\mathrm{t}}^{\mathrm{c}}$ ermítanme, en primer lugar, manifestarles a todos mi agradecimiento y expresarles la gran satisfacción, el gran honor que es para mí el que se me otorgue la máxima condecoración de la Asociación Española de Urología, de la Urología Española, como es la medalla de Francisco Díaz. Les doy las gracias de corazón a cada uno de los que forman parte de la comunidad urológica española y muy especialmente a su presidente, el Dr. Oscar Leiva persona a la que tengo gran estima tanto por sus cualidades personales como humanas. Muchas gracias. Oscar. Más de cuatro siglos han transcurrido ya desde que Francisco Díaz publicase su obra "Tratado de todas las enfermedades de los riñones, vexiga y carnosidades de la verga, y urinaria", libro venerable que se publicó en Madrid en 1588. Aquel hombre avanzado a su tiempo, que nació en Rioseras, no se conoce exactamente la fecha, fue entre 1510 y 1515, y que falleció en Madrid en 1590, se doctoró por la universidad de Alcalá y durante largos años ejerció la medicina y posteriormente se trasladó a la corte como cirujano del rey Felipe II.

Francisco Díaz era consciente del vigoroso impulso que la cirugía experimentó durante la baja Edad Media imprescindible para que durante el Renacimiento se desarrollasen las novedades quirúrgicas que traen consigo los siglos modernos. El espíritu de aventura y el afán de innovación fueron los motores que contribuyeron al gran desarrollo que experimentó el estudio de las afecciones urogenitales y que quedan recogidos en su obra.

Hay que destacar la contribución de Francisco Díaz al tratamiento quirúrgico de la litiasis. "La innovación quirúrgica como aventura" podría ser a los ojos del historiador actual, el epígrafe que define su labor científica. Esta labor preparaba con dos siglos de antelación la futura transformación del litotomista, tachada desde los tiempos de Hipócrates de charlatán, es miembro respetado de la comunidad médica y científica.

No hay duda, en la España del Siglo XV y hasta bien entrado el siglo XVIII se distinguían los médicos titulados universitarios, entre los que se encontraban los bachilleres, licenciados y doctores; los cirujanos (rivales de los médicos); los cirujanos-barberos (servidores de los médicos y con frecuencia peones suyos en esa pugna profesional) y los curanderos. El puesto de cirujano en la sociedad era notoriamente inferior al de médico, y más cuando éste podía ostentar el título de doctor.

Cervantes, en su novela "El juez de los divorcios", nos cuenta como una mujer alega que su matrimonio no es válido, porque quién se casó con ella dijo ser médico, no siendo más que cirujano.

Es natural que este espléndido progreso favoreciera el desarrollo y la posterior consolidación de la Urología, como especialidad médico-quirúrgica a finales del siglo XVIII.

A lo largo del siglo XIX la exploración macroscópica del cuerpo humano quedó concluida. En 1920, ninguna noción anatomo-descriptiva, era posible añadir a las que contenían los grandes Tratados de Anatomía. Pero el Anatomista ambicioso, como pensaba mi padre, el disector nato que quiere elevar a verdadera ciencia morfológica el conjunto de sus saberes descriptivos, ¿podía conformarse tan sólo con ordenarlos? Indiscutiblemente la respuesta tenía que ser no. La Anatomía Helénica de Galeno y la Renacentista de Vesalio, ambas descriptivas, sustrato imprescindible para conocer el cuerpo 
humano, tenían que evolucionar hacia una Anatomía topográfica y funcional, imprescindible para el desarrollo de la ciencia quirúrgica.

Los conceptos de "estructura", "estructura funcional", "forma", "forma funcional" y "sistema funcional", son fundamentales para interpretar la Anatomía moderna, la Anatomía aplicada a la Cirugía, en definitiva la Anatomía Quirúrgica.

Esta forma de interpretar la Anatomía, -la Anatomía como sustrato esencial de la técnica quirúrgica-, la paulatina incorporación de operaciones regladas y la creciente habilidad manual de los cirujanos, impulsaron el desarrollo operatorio de la Cirugía en general y de un modo especial de la Cirugía Urológica, que mi padre pudo vivir durante las décadas tercera, cuarta y quinta, del pasado siglo.

Mi padre, en esas charlas familiares propias de la sobremesa en las que el tema de mis estudios, se trataba con cierta frecuencia, me refería que tres hombres ponen en marcha la Urología como especialidad quirúrgica: J. Civiale, gran experto en la litotricia, su sucesor en el Hospital Necker Félix Guyón, maestro de prestigio mundial y su sucesor en la Cátedra de Urología de París, el HispanoCubano Joaquín Albarrán, el gran maestro de la Urología moderna.

A estos nombres puntuales les tenemos que añadir otros más que contribuyeron al desarrollo posterior de diferentes áreas como Nitze, inventor del cistoscopio; Lichtenberg, descubridor de la urografía intravenosa y Chevassu, de la pielografía ascendente; Fuller y Freyer descubrieron y perfeccionaron la técnica de la adenomectomía suprapúbica y McCarty e Iglesias de la Torre otro Hispano-Cubano éste, fueron los padres de la resección transuretral.

He dejado intencionadamente para el final a dos Urólogos Americanos Young y Huggins, que mantuvieron una relación de amistad con mi padre. Young fue el maestro indiscutible de la cirugía prostato-perineal y Huggins representa la mayor contribución, que hasta la fecha, se ha hecho al conocimiento del tratamiento del cáncer de próstata.

Permítanme que, una otro nombre a los recordados: el de Salvador Gil Vernet. Y el citarlo ahora no se debe a la relación familiar que a él me une, sino, objetivamente, por la labor callada con la que contribuyó de forma manifiesta al desarrollo de la urología, dándole verdadera dimensión científica a la especialidad. Acepten, pues, que en este acto institucional de la Asociación Española de Urología, viva yo el placer, y también el honor, de referirme a Salvador Gil Vernet, primero como padre y, posteriormente, como figura relevante de la urología española y mundial y que, en mérito a sus investigaciones, fue nombrado en Munich, en 1967, presidente de la Sociedad Internacional de Urología.

Como escribió don Miguel de Unamuno en su "Diario íntimo", la palabra padre se constituye en la mayor definición de amor. $Y$ en verdad el amor del progenitor para con sus hijos es el más grande, generoso y desinteresado de todas las posibles relaciones humanas. Y más aún será, cuando a la relación padre-hijo se une la de amistad. La amistad que nos unió, fue el motor indiscutible de la labor científica; la armonía que mantuvimos en nuestra amistad era consecuencia de la serenidad y de la espontaneidad propia de los genios que siempre mantuvo mi padre.

Su gran pasión fue la de investigar en el terreno de la Anatomía quirúrgica para, después aplicarla a la técnica operatoria. Es indiscutible que esta vida dedicada a la investigación médica implica crear armonía y así es como ésta presidió la relación de amistad que mantuve con mi padre. El siempre afirmó que la familia es el vínculo más estrecho y entrañable de la relación natural y que tal vínculo debe ser, más que un elemento de confianza, un aliciente para mantener esta relación con más cuidado y delicadeza que cualquier otra.

En verdad la relación que mantuvimos mi padre y yo fue, por así decirlo, un auténtico contrato tácito entre dos personas y especialmente por lo que a él respecta, sensibles y virtuosas. Y digo virtuosas porque los malvados sólo tienen cómplices, los lascivos, compañeros de libertinaje; los interesados socios; los políticos, partidarios. Sólo los hombres virtuosos tienen amigos: mi padre fue un gran amigo para mí.

Deseo concluir este apartado que podríamos denominar "Salvador Gil Vernet" padre y amigo, primero cantando a la amistad, a la que considero por encima de las demás virtudes, y pidiendo la gracia de no ver nunca como se pierde. No obstante, y aunque tanto duela la pérdida definitiva, es necesario vivirla para conocer, con aceptación, el dolor por el amigo perdido. 
Y ahora, con la máxima objetividad, con la verdad de la que nos hablaba Machado, os ruego que compartáis conmigo el recuerdo de algunas etapas de la vida de Salvador Gil Vernet como estudiante y médico, como investigador y como docente universitario.

Como otros niños de su pueblo natal, Vandellós, en la provincia de Tarragona acude a la escuela nacional en la que cursa sus primeros estudios, $y$ ya en esta época nace una incipiente vocación por el estudio de la naturaleza. En una de sus cartas que con amor conservo, me dice: "Llevaba ya dentro de mí un deseo ferviente de consagrarme a la labor científica, sentía irresistible inclinación por el estudio de las ciencias naturales, en particular por la botánica que me cautivaba. A ella dedicaba mis vacaciones veraniegas durante las cuales llegué a coleccionar un número considerable de especies, pertenecientes algunas de ellas a familias difíciles de clasificar para un principiante".

La ilusión de mi padre era la de llegar a ser Catedrático de Ciencias Naturales en un Instituto, pero diversos motivos familiares hicieron que no se llegase a cumplir este propósito.

En otra ocasión, relacionada con el mismo tema, me comentó: "El destino, o mejor aún, la acción inexorable del ambiente, truncó mis inclinaciones por la naturaleza que fueron sustituidas por el estudio del cadáver humano al que he dedicado mi existencia a partir de los 18 años, hasta el punto de que se me puede aplicar la frase que se atribuye a Letamendi "Menos el papel de cadáver he desempeñado todos los oficios de la sala de disección".

No cabe duda de que aquellos años dedicados a la contemplación directa de la naturaleza, influyeron decisivamente en su formación, desarrollándose en él un espíritu de observación, que es fundamental para el estudio de la medicina y especialmente para la investigación. Alguna vez, mi padre me comentó que quien no siente emoción y no se extasía ante la contemplación de los grandes espectáculos y panoramas que nos ofrece la naturaleza, poco podrá hacer en la investigación científica biológica.

El 30 de Junio de 1915, obtiene el grado de Licenciado en Medicina y Cirugía con sobresaliente. Durante sus años universitarios, fue alumno interno de la Cátedra de Anatomía y posterior- mente en la de patología quirúrgica. Por último también fue alumno interno en el antiguo Hospital de la Santa Cruz, en el que, desde 1906 funcionaba el servicio de Urología más importante de Barcelona. Tras concluir la carrera prosiguió su formación urológica en la Clínica de un cirujano más especializado en la patología urogenital. Mi padre, en aquellos tiempos, se ayudaba con los limitados ingresos que obtenía de un consultorio que tuvo en la calle Escudellers. Atendía a los pacientes por cincuenta céntimos la visita...

Pero su vocación se iba orientando más y más hacia la investigación y docencia, que dirigirá hacia la Anatomía. En efecto, en 1919 don Salvador, fue nombrado auxiliar temporal de la Cátedra de Anatomía, actividad docente que desarrolla de forma gratuita. Mi padre recordó siempre aquella época con una gran satisfacción. Era un hombre que se movia por impulsos, por deseos de ser o conseguir determinadas metas.

Son muchos, claro está, los impulsos que pueden movernos, pero acaso el más fuerte de todos es el del amor, que en este caso, es distinto al familiar. Se trata del amor que él sentía, el amor que se siente, por la investigación. Este sentimiento ciega a las demás motivaciones, de modo que el ser humano, cuando se mueve por amor, vive centrado en éste y lo considera una prioridad decisiva.

Un año más tarde, en 1920, oposita para la Cátedra de Anatomía de Madrid, tenía tan sólo 28 años; el Tribunal estaba presidido por Don Santiago Ramón y Cajal, que en el acto de la votación manifestó: "de acuerdo con mi conciencia me abstengo de votar". Posteriormente el Ilustre Histólogo explicó su abstención diciendo que a su juicio, ningún opositor presentaba pruebas de ser un investigador científico; unos, por su edad avanzada era difícil que pudieran serlo; otros, por ser demasiado jóvenes, no tienen aún tiempo para serlo. A título anecdótico me contaba mi padre que Don Santiago en aquella ocasión le dijo: "En vez de estudiar tanta Anatomía, debería ir a Burgos a aprender castellano". Sin duda debido a su arraigado acento catalán, pero indiscutiblemente, y esto lo puedo afirmar de forma categórica, mi padre era un español por encima de todo.

Los sentimientos son muchas veces absolutamente compatibles entre sí. 
Tras un periodo de seis años que se suspendieron las oposiciones a Cátedras Universitarias, en 1926 obtiene por oposición la Cátedra de Anatomía de Salamanca y dos años más tarde la de Barcelona. A partir de esta fecha desarrolla simultáneamente la actividad clínica Urológica en el Hospital Clínico.

Durante todo este periodo y hasta su muerte, mi padre tiene una estrecha relación con Cajal. Nació en él una profunda admiración que perduraría durante toda su vida. Para nombrarlo siempre utilizaba el término "El Maestro".

Preparando este discurso he encontrado una de las primeras cartas de Don Santiago, del 5 de Octubre de 1925, en la que hace referencia a la neuroanatomía del plexo pélvico y a la regeneración nerviosa en respuesta a otra en la que mi padre le planteaba algunas cuestiones en relación con el tema. Hablamos de 1925 cuando él ya hacía referencia a esta parte de la neuroanatomía que muchos, muchos años después se ha popularizado con el término de "bandeletas".

EI Investigador. La labor ingente queda recogida en su tratado titulado "Patología Urogenital", publicado en tres volúmenes, a excepción de las "Enfermedades de la vejiga urinaria y de la porción terminal del uréter" que no pudo ser editado y que completaría la obra. A título puramente representativo quiero referir algunos comentarios que han sido emitidos por Históricos personajes de la Urología mundial en referencia a la obra de mi padre:

- El Profesor Chevassu refiere: "Esta obra está destinada a constituir un monumento capital de la ciencia Urológica".

- El Profesor Lowsley comenta: "Es una maravillosa publicación y la usaré como libro de consulta".

- El Profesor Young escribía, poco antes de su muerte, al comentar el primer volumen de la obra: "He leído este maravilloso libro, con el máximo interés. Es realmente una obra monumental. Las ilustraciones son las más sorprendentes que jamás se hayan publicado en un texto de Medicina. Su contribución al estudio de la Patología y la Cirugía de la próstata es verdaderamente grandiosa".

Quiero concluir con esta serie de citas, que por razones de tiempo no prolongo, con las del Premio
Nobel de Medicina de 1956, Charles Huggins y la del Prof. Boccon-Gibod. El Profesor Huggins en una carta que le escribió a mi padre el 6 de Diciembre de 1961, y que yo guardo con gran cariño, le decía: "Estimado Don Salvador, su obra es un trabajo definitivo sobre una materia que vivirá siglos. Verdaderamente me ha impresionado, y de un modo especial el carácter penetrante de sus observaciones. Mi equipo y yo lo consideramos como la personificación de un genio catalán, un genio español, un segundo Cajal. Uno de los grandes privilegios de mi vida ha sido el poder conocerle y entablar una relación personal. Le invito a visitar el laboratorio que dirijo, el laboratorio para la Investigación del Cáncer de la Universidad de Chicago, para que imparta una conferencia, pueda revisar nuestras investigaciones y estar unos días entre amigos y admiradores".

El Profesor Boccon-Gibod, en el discurso que disertó en el Congreso de la Asociación Española de Urología, de 1999, con motivo de la Medalla Francisco Díaz, que le fue otorgada comentaba: Es interesante observar que el mismo fenómeno (se refería a las aportaciones de Francisco Díaz al avance de la Urología y especialmente a su tratado), se ha reproducido cuatro siglos después con otro español; me refiero a la obra de Salvador Gil Vernet, sobre la Anatomía y las afecciones de la próstata, publicada a mediados de los años 50; desafortunadamente nunca traducida del Español. Ha sido y es soberbiamente ignorada por los anglosajones, que llegaron a resultados similares tres o cuatro décadas más tarde, plagiándolo sin ninguna vergüenza y sin citarlo jamás. Y termina diciendo, le debo a mi Maestro el Profesor STEG, que estuvo una temporada con el Profesor Gil-Vernet, en Barcelona, el haber descubierto lo que sigue siendo uno de los textos sobre Anatomía y patología prostática más impresionante y grandioso de la segunda mitad del siglo $\mathrm{XX}$.

Creo que la importancia de esta obra no estriba en la recopilación de todo lo escrito sobre la Biología y la Patología de la próstata, no es una enciclopedia; a nuestro modo de ver su valor radica en que en ella queda perfectamente reflejada la labor científica de muchos años en la clínica y en el laboratorio que se traduce en la aportación de hechos y conceptos nuevos. 
EI Universitario, el Docente. Creo conveniente recordar algunos hechos acaecidos en la Universidad Española que mi padre en alguna ocasión me refirió y que hoy, y guardando algunas distancias, no debemos reproducir. Se refiere al problema de la autonomía de la Universidad de Barcelona y ante el sesgo que tomaban los acontecimientos de los cuales era perfecto conocedor, defiende la solución de crear dos Universidades: una española y otra catalana... Dicha solución puede parecer extraña pero en aquellos tiempos era la única manera de evitar cualquier tipo de segregación política e idiomática.

El 14 de Agosto de 1936, en los inicios de nuestra incivil Guerra Civil, tenía que abandonar España en un barco francés, el Cortés II, que lo lleva a Marsella. Cuando regresa a España, en 1939, se dedica íntegramente a la Universidad. Escribe numerosos artículos referidos a las cualidades que debe tener un Profesor Universitario con relación a la abnegación y al espíritu de sacrificio, el rigor y a la resistencia física, a la higiene mental, a la emoción ante un hecho nuevo, a la cultura, al conocimiento de idiomas, a las publicaciones y a la asistencia a los Congresos así como a la importancia del ambiente.

Sin duda alguna, el ambiente, en su triple aspecto, moral, intelectual y físico, es el factor primordial en la actividad docente e investigadora, actividades que debe desarrollar un Profesor Universitario. El ambiente no crea genios, investigadores y docentes; pero cuando este es bueno favorece el desarrollo, y cuando es adverso lo dificulta, dando frutos incompletos y a veces consiguiendo malograrlos.

En numerosas ocasiones mi padre me ha hablado del daño que el aislamiento de nuestro País le ha originado a la Universidad, a la Investigación y a la Cultura en general. Este impide divisar nuevos horizontes y produce un enquistamiento intelectual, impermeable a toda renovación. Ya en aquella época mi padre defendía la política de europeizar España estableciendo relaciones culturales con los países vecinos y facilitando la salida de nuestros investigadores al extranjero. Defendió y participó decisivamente en la creación de un bloque cultural latino consiguiendo en 1948 fundar la Sociedad Urológica del Mediterráneo Latino como la mejor arma para luchar contra el silencio y la indiferencia que nos aislaba e incomunicaba con el resto de Europa y que se sintetizaba en la amarga frase: "Europa termina en los Pirineos". En una ocasión me leyó una frase de Ortega que a él le gustaba pues reflejaba su forma de pensar en lo que a la universidad, a la investigación y al desarrollo cultural se refiere: "Sólo la solución de construir una gran nación con el grupo de los pueblos continentales volvería a entonar la pulsación de Europa" y me aclaraba, "esta unión no requiere la desaparición de las características peculiares de cada pueblo europeo; al contrario, como afirma este pensador: "Exige la permanencia activa de este plural que ha sido siempre la vida de Occidente":

Ortega y mi padre ya intuían lo que hoy es la Unión Europea.

He querido que esta pequeña disertación, aunque grande para mí emocionalmente, esté dedicada fundamentalmente a mi padre. Sólo me queda referir que toda la dedicación que he puesto en la Urología ha sido gracias a las enseñanzas que de él pude aprender. He querido que todas ellas, en relación con la Anatomía Guirúrgica, pudieran tener un resultado práctico y así creemos que ha sucedido en cada una de las aportaciones que hemos realizado.

He intentado aportar algo nuevo al introducir procedimientos quirúrgicos que han servido para perfeccionar los que no eran suficientemente efectivos o que en otros casos no existían.

$\mathrm{El}$ protocolo de este tipo de acto, conlleva que el galardonado comente su vida científica, tarea que me resulta algo embarazosa. Mi vida, como ya he referido, ha estado marcada por las influencias de mi padre, a las que no podía ni debía sustraerme, así como por el mundo que me ha rodeado. El fenómeno biológico de la diferenciación celular se ha comparado al de ser médico. Esta es debida a dos factores, el código genético y el ambiente. Al igual que en el desarrollo del embrión dos cosas son necesarias para el desarrollo del cirujano. La primera, es la de tener una habilidad intrínseca a la que se le asocie la capacidad de sufrir las maduraciones necesarias para alcanzar un alto grado de diferenciación. La segunda, es el ambiente adecuado para cada nivel de desarrollo. Por consiguiente, además de la vocación genética es necesario no apartarse del 
ambiente Universitario y vivir en comunidad con un Hospital acorde a la maduración deseada. Este es el ambiente del que hablaba mi padre.

Gran parte de mi quehacer profesional to he dedicado a la producción de películas científicas. Creo que el cine es el medio audiovisual más idóneo, más didáctico que se puede emplear en la formación del cirujano. Creo en la imagen como medio de comunicación universal, aunque para lograrlo cada imagen debe ser autosuficiente para la comprensión del mensaje que se desea exponer. Para que sea realmente útil, tanto para la enseñanza de la cirugía como para informar y dar a conocer los avances en el campo de la investigación quirúrgica, es fundamental que las imágenes transmitidas en directo a través de los nuevos formatos, tengan una alta calidad de resolución.

De no ser así difícilmente se le puede exigir al cirujano en ciernes que llegue alcanzar el máximo de perfección, que domine la técnica quirúrgica y que consiga hacer de cada operación una obra de arte, pilares fundamentales y razón de ser del cirujano.

Con la llegada del color, que al igual que en la pintura vale más, que la palabra, se pueden crear imágenes que nos ayudan a sentir, a vivir, a compartir con el cirujano la propia intervención. Con la llegada del sonido, la palabra seduce, reafirma y da más vida a la imagen. Esta es la esencia, la razón de ser del audiovisual; un aliado para observar, explorar e intervenir en aquellos mundos donde impera la precisión. Las aportaciones quirúrgicas, las innovaciones técnicas, la cirugía en general, que precisan de una fuerza viva de expresión, son las más beneficiadas, ya que los procedimientos audiovisuales nos permiten enseñar precisamente aquello que no es posible aprender en los libros.

El sentido de la perfección, que es una de las cualidades que debe tener el cirujano, me llevó a introducir en la década de los años sesenta el microscopio operatorio en cirugía urológica. Gracias a la magnificación de imágenes y visión estereoscópica pudimos mejorar la calidad de algunas intervenciones sobre macroestructuras en el niño y poder trabajar con una mayor precisión sobre microestructuras haciendo así posible nuevas cirugías como el trasplante de testículo, puesto que pudimos anastomosar vasos de un diámetro inferior a un milímetro así como la cirugía de las arterias renales periféricas como la arteria interlobar, la cirugía de la impotencia, de la vía espermática y del pene curvo, entre otras.

La microcirugía, junto a los avances en la conservación de órganos, ha hecho posible la reparación de un órgano fuera del cuerpo humano, -la cirugía extracorpórea-, con lo que se cumplió el vértice tantas veces soñado por el cirujano de realizar una cirugía totalmente exangüe, atraumática y haciéndolo sin prisas, puesto que una vez reparado, el riñón puede devolvérsele al paciente horas, o incluso días después, porque así ha sucedido.

La magnificación de la imagen que, por cierto, la actual cirugía laparoscópica, es el mayor beneficiario, proporciona detalles de interés quirúrgico y también elementos para la autocrítica.

El M.O. que es uno de los más importantes avances tecnológicos del pasado siglo, es imprescindible para la cirugía experimental en el pequeño animal y resulta básica para el progreso de la ciencia médica, sin la cual no hay método de investigación, ni medicina ni cirugía científica.

La investigación quirúrgica no sólo ha contribuido al desarrollo de la cirugía, haciéndola más humana y más segura, sino también ha hecho posible el desarrollo de otras ramas de la medicina y los trasplantes de órgano son un claro exponente ya que a partir de ellos se ha desarrollado la inmunobiología, la inmunogenética, la inmunosupresión, la conservación de órganos, etc.

La microcirugía de importancia en la formación del cirujano, es de aprendizaje largo y difícil y obliga a la adopción de una nueva filosofía. Es una escuela de autodominio, de paciencia, de precisión y perfeccionamiento en la que todos somos alumnos. Todo ello nos permitirá lograr una sólida técnica para la ejecución impecable de toda operación y, conseguir esa obra de arte a la que aludía, porque el cirujano, entre los médicos, es el que vive la más grave de sus responsabilidades: la vida de un ser humano depende durante un brevísimo espacio de pocos minutos, de su sólida técnica.

Creo, al igual que otros predecesores, que es el cirujano y no la operación el que cura al enfermo, y lo comento hoy en ese acto porque en las últimas décadas se ha puesto, digamos, de moda el 
decir que la operación, la técnica quirúrgica, es una faceta poco científica de la urología. En este sentido quiero resaltar, especialmente para los más jóvenes, que hemos leído nombres que aparecen en revistas, monografias y tratados que, en algún momento nos han podido deslumbrar, y que opinan que el cirujano es demasiado esclavo de la técnica, que es el lado servil de la actividad quirúrgica y que debería ocuparse más en conocer la biología molecular y otros saberes muy eruditos y complejos.

Creemos que ambas formas de ver la Medicina, la Cirugía, la Urología, son, sencillamente, complementarias. Lo que ocurre, es que a veces, detrás de una defensa desequilibrada está una deficiencia en lo que es la actividad quirúrgica. Es importante resaltar que nuestra especialidad es médico-quirúrgica y que su componente técnico es fundamental.

Cuando un residente termina su periodo de formación puede ser importante que sepa patología molecular, las mutaciones del DNA, los radicales libres, pero es imprescindible que sepa como resolver los problemas quirúrgicos que con toda seguridad se le van a plantear. Debemos, pues, ser honestos, con las gentes que formamos. Un egregio Catedrático de Cirugía como Puente Domínguez decía en un editorial: "yo insisto en que la técnica, la operación que se hace en el quirófano es el acto esencial de todo cirujano y el fundamento de su profesión". Y prosigue diciendo: "Una técnica bien realizada cura al enfermo, y una técnica mal hecha lo mata, así de simple". Los cirujanos sabemos que esto es dramáticamente cierto y por ello conviene que de vez en cuando nos lo recuerden. Y Spencer añade: "Mi experiencia como
Asesor de Comités Hospitalarios en Estados Unidos, es que los errores cometidos durante la operación son todavía causa de elevada mortalidad y morbilidad quirúrgicas".

Lo primero fue el verbo...? lo primero fue el cirujano!. No se puede, no debemos explicar la práctica quirúrgica, como una simple aplicación técnica de la ciencia, sino la ciencia desde la práctica. La urología es formalmente una actividad, y la ciencia quirúrgica urológica no puede entenderse más que como el resultado de esta práctica.

La urología ha comenzado a verse a sí misma no sólo como exerética, sino también como restauradora y creadora de un orden funcional nuevo. Así, cuando un cirujano sustituye una vía urinaria por un segmento de intestino está instaurando un orden funcional nuevo, y cuando lleva a cabo un trasplante intenta ir más allá de lo que es el orden natural.

Señores, gracias al esfuerzo de innumerables predecesores estamos asistiendo a la transfiguración de la cirugía, sin duda caminamos sin detenernos hacia un orden y una concepto más bello y más profundamente humano.

Señoras, señores, muchas gracias por su presencia y por su atención, a la par que reitero mi agradecimiento por la distinción que se me ha otorgado.

\footnotetext{
Dr. D. J.Mํㅡㄹ Gil-Vernet

Servicio de Urología

Clínica San José

Monegal, 1

08023 Barcelona
}

(Trabajo recibido el 18 de octubre 2002) 